\title{
CONTROVERSIES IN TEACHING ENGLISH GRAMMAR
}

\author{
Renu Singh \\ Department of English Education
}

\begin{abstract}
Although grammar has long ben taught and learnt, it has, recently, been a matter of debate whether it is worth to teach for languag development. This article presents the controversies regarding teaching English grammar home and abroad. Additionally, it also overviews various trends in grammar teaching.
\end{abstract}

\section{Keywords}

Grammar, behaviorism, learning, acquisition, explicit, implicit

\section{Introduction}

The phrase 'grammar' has had a long tradition from the early days of literate civilization until now. It has been perceived and interpreted by different scholars in different ages with different viewpoints. The term 'Grammar' etymologically goes back to a Greek work "grammatika or 'grammatike techne' which means 'the art of writing'. The Greeks viewed grammar to be a branch of philosophy concerned with the art of writing ' By the middle ages, grammar had come to be regarded as a set of rules, usually in the form of a textbook, dictating correct usage. Traditionally, grammar meant a set of normative prescriptive rules in order to establish a standard of correct 'usage' and was taken as the art and the science of language. The traditional grammarians, in this sense, were the law - givers until the nineteenth century. On the contrary, grammarians of the twentieth century brought revolutionary changes to the term grammar and took away from the definition given by traditional grammarians. They agreed that grammar should be descriptive that can describe language thoroughly at different levels. The structural grammarians contributed to it by innovating the concept of Immediate Constituent (IC) analysis and grammar became the study of organization of words into various combinations such as 
phrases, sentences and complete utterances. Furthermore, the revolutionary arrival of Chomsky with has book Syntactic Structure (1957) brought another drastic change to the term and viewed it with new dimension. He emphasized on sound meaning relation in language.

There should be no doubt that grammar is one of the major components of language which refers to correctness in language. In other words, it describes and shapes language phonologically, morphologically, syntactically and semantically. Needless to say, grammar taught in isolation is never significant. There are numbers of evidences recorded in history that promote grammar teaching in communicative context or social setting. Keeping this view in mind, syllabus designers are now designing language syllabus focusing form and function of language together . However, with regard to the importance of grammar in language teaching, there are completely opposing views. A newspaper heading 'Grammar is back' (Bygate et al 1994, p. 1) better provides the evidence that supports the fact that grammar teaching has some unsettled controversies for a long time. The two views have been described briefly below:

\section{View in favor of teaching grammar}

If we see the history of teaching grammar we find many evidences that have emphasiesed the role of grammar in foreign language teaching. During Greek and Latin periods, the study of a language primarily meant the study of its grammar in order to enable the learner to read and to write correctly. Similarly, the special attention was given to grammar in language teaching by structural linguists. Wilkins (1972) opines that the aim of the linguist to reveal the system of the language, the langue and the language teacher to enable people to learn it. Even the Chomskyan revolution in linguistics has kept grammar at the centre of linguistics interest.
Many classroom researches have been carried out which show an ample evidence of grammar teaching effectively improving English learners' accuracy in the use grammatical items such as articles, tense, clauses etc. For example, Cardierno (1995) and Doughty (1991) have demonstrated that explicit instruction can increase students' accuracy in the production of past tense forms and relative clauses (Cited in Cowan, 2009, p. 30). There is no doubt that a knowledgeimplicit or explicit - of grammatical rules is essential for the mastery of a language (cited in Thornbury, 1999, p. 14). Tom Hutchinson has the similar opinion when he says, 'sound knowledge of grammar is essential if pupils are going to use English creatively' (ibid).

As mentioned above, the instruction of grammar is very much important in order to enable second/foreign language learners to have very sound knowledge of the language they are learning. However, it is a matter of debate whether it is taught explicitly or implicitly. In explicit way of grammar teaching, the rules of the target or second language are taught or explained to learners where as in implicit way of grammar teaching, they are taught to come up with the rules from the language exposure given to them. In other words, explicit grammar teaching is called deductive instruction and implicit grammar teaching is called inductive instruction. Norris and Ortega (200o) have analyzed forty nine studies which has shown that explicit teaching produces better and long - lasting learning than implicit teaching (Cited in Cowan, 2005, p. 31).

\section{View against teaching grammar}

To quote Krashen, 'The effects of grammar teaching .......... appear to be peripheral and fragile' (1999, p. 14). This is the claim made by Krashen with a theory of L2 learning in the 1970s. The theory called Input Hypothesis rejected the value of teaching grammar and advocated the two processes by which adults obtain knowledge about language 


\section{R. Singh}

i.e. acquisition and leaning. Acquisition is a subconscious process identical in all important ways to the process that children utilize in acquiring their native language. On the contrary, learning is a conscious process that results in knowing about a language These two processes never interact; only acquired knowledge can be used in spontaneous conversation in the L2. Therefore, the theory implies that grammar instruction is pointless or peripheral and fragile (ibid). He views that foreign language learners themselves point out the rules of grammar therefore the rules turn to be acquired knowledge because learned knowledge is peripheral and fragile or just accumulation of learned grammatical rules. Later, Krashen developed a classroom approach to teaching an L2 called the Natural Approach which gives maximum opportunities to students to receive 'comprehensible input' through extensive reading for pleasure.

Krashen's theory has been criticized by many L2 researchers. Among them, McLaughlin has pointed out that the cornerstones of his theory- acquisition and learning are not clearly defined and full of weaknesses (Cowan 2009).

\section{Trends in grammar teaching}

Grammar teaching in general has a very long history behind and it has tremendously changed over the centuries. Drastic changes and innovations were brought in grammar teaching mainly in twentieth century. Consequently the experts or architects of language teaching methods have been preoccupied with the following two basic design decisions concerning grammar teaching:

Should the method adhere to a grammar syllabus?

Should the rules of grammar be made explicit?

There are various ways they answered the questions which help distinguish the different methods /trends from each other. The different trends in grammar teaching are:

\section{Grammar translation method}

The earliest known method of language teaching is grammar translation and it was considered to be a method without any theory, despite the fact it influenced foreign language teaching from 1840 os to 1940 os. It emphasized grammar for instruction. Grammar - Translation courses followed a grammar syllabus and lesson began with an explicit statement of the rule, followed by exercises along with translation into mother tongue.

\section{Direct method}

Direct method came into existence in the mid-to late -nineteenth century, challenged the way that Grammar - Translation had focused on the written language. Also known as a 'natural' method, it gave priority to oral skills and followed a syllabus of grammar structures. It strictly avoided explicit grammar teaching and translation. The learners were supposed to learn the grammar in the same way as children picked up the grammar of their tongue.

\section{Audiolingual method}

Audiolingualism brought some modifications in the thoughts advocated by Direct Method and stayed tuned to its belief in the primacy of speech. Its theoretical base was taken from behaviorist psychology which considered language learning simply as a matter of habit formation. It was entirely based on patternpractice drills.

The revolutionary thoughts of Noam Chomsky, in the late 1950s, that language ability is not habituated behavior rather an innate human capability, shook the foundation of audiolingualism. The view that human beings are equipped with language acquisition Device (LAD) brought another significant change in grammar teaching. 
Krashen's Natural Approach stood against formal instruction of grammar syllabus and explicit rule giving. His approach emphasized on maximum exposure of comprehensive input with the thought that innate processes convert the input into output in course of time. In other words grammar, teaching was found irrelevant in the Natural Approach.

\section{Communicative Language Teaching}

Communicative Language Teaching (CLT) was developed in the 1970 s with the belief that communicative competence consists of more than simply the knowledge of the rules of grammar. Despite the fact, CLT in its shallowend version did not neglect grammar teaching. It emphaised on functional labels such as asking for permission, making suggestions, requesting, describing events, talking about yourself etc. In other words, explicit attention to grammar rules along with communicative practice co-existed together. Even Chomsky had claimed that language was rule governed and theorists suggested that explicit rule giving may have a place in teaching. This claim made grammar rules reappear in course books and grammar teaching re- emerged in language classrooms.

On the other hand, the other part of CLT, deep-end CLT neglected grammar syllabuses and grammar instruction. N. S. Prabhu, a major proponent of the view, in his Bangalore Project, advocated the natural acquisition processes which allow students to do tasks of language without formal grammar instruction. After all the ultimate goal of language learning is to be able to communicate message by explaining a map or writing something. The deep- end CLT is known as task - based learning which focuses on grammatical forms and helps expand grammatical knowledge through speaking and writing and corrects students without disturbing their ongoing communication.

However, grammar teaching in context came later as a reaction against 'focus on form' and was supported by Nunan. He strongly advocated an organic approach that enables learners to become active explorers of language. Moreover he has suggested some of the operational principles of organic method of teaching grammar in context.

- exposes learners to many examples of authentic language;

- provide them with opportunities to use language that they have not been exposed to or have not practiced in any systematic way;

- give them opportunities for collaborating with other students and comparing their efforts and

- let them revise and compare their final efforts with the language in the original text.

The above mentioned principles advocated by Nunan (Cited in Murcia et al. 1988) are not based on any theory of L2 learning or classroom research. Instead they are entirely intuitive to foreign language teachers (FLT) and somehow they rely heavily on collaboration among students and emphasize implicit grammar teaching.

\section{Conclusion}

Grammar is one of the major components of language that has ever existed directly or indirectly. The value of teaching grammar has been debated very recently. In fact the history of language teaching is essentially the history of the claims and counter claims for and against grammar teaching. The differences in attitude to the role of grammar underpin difference between methods, teachers and learners. Moreover, it is a subject that everyone involves in, language teaching and learning. Regardless the fact that grammar is controversial, the experts or architects of language teaching methods have been advocating and innovating different methods of teaching grammar for centuries. As there 


\section{R. Singh}

is no end of excellence, a grammar teacher should not be confined to a single method because a method which is appropriate for one grammatical item or a class may not necessarily suit another. Similarly a method which is suitable for one grammar teacher may not be useful for other teachers. However a grammar teacher needs to have a very sound knowledge of different methods of grammar teaching being quite enthusiastic resourceful and imaginary she/ he could guide or facilitates students to develop communicative skills for interaction globally. In recent times CLT has been widely used to teach grammar in context. Likewise a great number of articles and conference talks have been contributing year-wise for the effective teaching of grammar and updating the practitioners around the globe.

The different trends in grammar teaching appeared in different times in the global scenario and they have undoubtedly influenced grammar teaching in Nepal. From translation method to communicative language teaching, each has been used by language teachers according to time and need. Whether it is taught at school level or college level, English language teaching professionals follow different ones at different times applicable to their contents. Instead of being entangled to one special trend they practice different trends to deepen their knowledge academically and professionally.

\section{References}

Bygate, M., Tonkyn A. \& Williams, E. (eds.) (1994). Grammar and language teacher. New York: Prentice Hall.

Cowan, R. (2009). The teacher's grammar of English. Cambridge: CUP.

Murcia, C . \& Hilles, S . (1988). Techniques and resources in teaching grammar. New York: OUP.

Thornbury, S. (1999). How to teach grammar. London :Longman

Ur. P. (2005). A course in language teaching. Cambridge: CUP.

Wilkins, D. A. (1972). Linguistics in language teaching. London: Edward Arnold.

\section{The Author}

Renu Singh is a Lecturer in English Education in Thakur Ram Multiple Campus, Birgunj where she has been teaching for the last ten years. At present she is teaching 'Grammar for Teachers of English' and 'Academic Writing. To her credit, she has co-authored a title on 'Academic Writing'. She has also published a couple of articles on in ELT Today, Journal of NELTA Birgunj. She has been associated with NELTA as a life member. 